\title{
UNDERSTANDING VARIATION IN REACTIONS TO Displays OF AlLEgIANCE
}

\author{
Daniel J. Kruger1, Michele Day ${ }^{2}$, Ailiya Duan², Anna Heyblom², Dora Juhasz², \\ Stephanie Misevich ${ }^{2}$, Camile Phaneuf ${ }^{2}$, Claire Saunders ${ }^{2}$, Peter Sonnega ${ }^{2}$ \& Vibra \\ Sreenivasa ${ }^{2}$ \\ 1 Population Studies Center, University of Michigan, Ann Arbor, Michigan \\ ${ }^{2}$ Literature, Science and Arts, University of Michigan, Ann Arbor, Michigan \\ kruger@umich.edu
}

\begin{abstract}
Sports team rivalries involve expressions of evolved psychology related to in-group loyalty and inter-group competition. ESPN ranked the University of Michigan-Ohio State University football rivalry as the greatest North American sports rivalry. Toledo, Ohio is geographically closer to Ann Arbor, MI (UM), than to Columbus, OH (OSU) and conventional wisdom holds that team loyalty is divided among local residents. Previous observational research of thousands of individuals in Toledo indicated that no one simultaneously wore apparel from the two competing teams. Inspired by these observations, a second study examined reactions to displays of mixed loyalty vs. consistent loyalty. When a research confederate wore clothing featuring both UM and OSU, he elicited more attention and reactions than when wearing equivalent outfits featuring just one of the universities. The current study examines factors explaining individual differences in attention to displays of allegiance to rival groups, whether consistent or mixed. We made several predictions for explaining variation in reaction rates based on evolved coalitional psychology. We predicted that men, young adults in the typical undergraduate age range (18-25), and those wearing university merchandise themselves will have higher reaction rates to the confederate than women, individuals in other age groups, and individuals not wearing university merchandise respectively. These hypotheses were generally supported by our observations $(n=1292)$. Controlling for experimental condition, reaction rates were higher overall for men, young adults, and those wearing university merchandise themselves. The highest reaction rates were by young adult men wearing university merchandise, to the mixed condition.
\end{abstract}

Keywords: Inter-group competition, observational research, loyalty, allegiance 


\section{INTRODUCTION}

Inter-group competition and in-group loyalty are prominent behavioral themes across social species (van der Dennen, 2002). Competition between different groups and alliances was a strong selection pressure for human ancestors. Once our ancestors achieved ecological dominance over other species, competition with other humans, both within and between groups, became a principal concern and strong selection pressure (Alexander, 1979). Forming alliances was advantageous, as coalitions with other individuals promote acquisition of resources, territories, and mates, all promoting reproductive success (Kenrick, Li, \& Butner, 2003).

Social psychologists have recognized the importance of group loyalty as a fundamental aspect and product of socialization for nearly a century (e.g., Bogardus, 1924). Coalitional biases are extensively documented (see Ruffle \& Sosis, 2006) and even superficial criteria can lead to group differentiation, costly contributions to the ingroup, and discrimination in favor of in-groups and against out-groups (Sherif, 1966; Wetherell, 1982). Evolved coalitional psychology is distinguished from other cognitive adaptations in that group membership creates motivation for conflict with and exploitation of out-group members (Kurzban \& Leary, 2001). Even trivial criteria can quickly create in-group/out-group differentiations and deep emotional attachments to in-groups (Brewer, 1979; Ostrom \& Sedikides, 1992; Tajfel \& Turner, 1979).

Professional and collegiate team sports are a venue for the manifestation of in-group loyalty and inter-group competition influenced by our evolved coalitional psychology (Kruger, Wang, \& Wilke, 2007; van der Dennen, 2002; Winegard \& Deaner, 2010). People typically have allegiance to only one team in a set of competitors, rather than switching loyalties depending on wins and losses (Richardson \& O'Dwyer, 2003). Athletic team loyalty is displayed through names and logos in clothing and other paraphernalia (Lindquist, 2006). New players don the team uniform in public loyalty building rituals such as a staged public signing event (Trice \& Beyer, 1984). Humans are likely to have evolved psychological coalition-detection mechanisms that are sensitive to indicators of alliances (Kurzban \&Leary, 2001), such as paraphernalia displaying names and logos.

\section{The Toledo War and the Modern Manifestation of the Michigan-Ohio Conflict}

The United States' Northwest Ordinance of 1787 established the Northwest Territory and stated that the territory would eventually be divided into a northern tier and a southern tier of Northwest states, with boundaries running due East and West from the southern tip of Lake Michigan. Ohio became a state in 1803, with a special proviso in its constitution claiming the entire bay of the Maumee River as part of the new state. When the Michigan Territory petitioned the U.S. Congress for statehood in 1835, it also claimed this area, in accordance with the Northwest Ordinance. Both sides mobilized militias to enforce their claim to the disputed territory, although direct military conflicts were rare, as the natural barriers of the Maumee River and the Great Black Swamp usually separated the militias.

The U.S. Congress intervened, granting the contested Toledo Strip to Ohio and expanding the Upper Peninsula of Michigan as compensation, at the expense of the Wisconsin Territory. Ohio had voting representatives in Congress, as it was already a 
state, whereas Michigan did not have congressional votes. The other southern tier states, Indiana and Illinois, were concerned about losing territory. If the dispute were settled in favor of Michigan, confirming the legal precedence of the Northwest Ordinance, Illinois could lose the City of Chicago to Wisconsin and Indiana could effectively lose direct access to Lake Michigan.

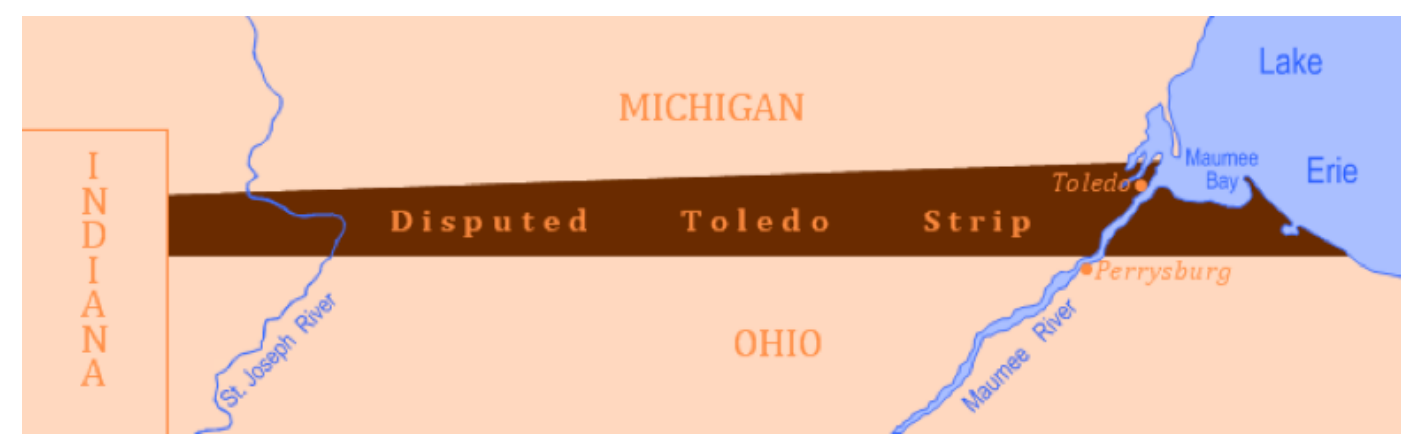

Figure 1. Area claimed by both Michigan and Ohio.

Note: Map created by Wikimedia user "Drdpw" and used under the terms of Creative Commons license BY-SA 3.0.

Toledo is now a mid-sized city in Lucas County, Ohio, a county named after Robert Lucas, the governor who denied the Michigan Territory's claim to the area. The historical territorial conflict between Michigan and Ohio reverberates among current Toledo residents in the divided loyalties between the University of Michigan Wolverines and Ohio State University Buckeyes, the athletic teams of the flagship public universities in their respective states. A City with its northern limits at the Ohio-Michigan border, Toledo is actually closer to Ann Arbor, MI ( $85 \mathrm{KM})$ than to Columbus, OH (222 KM), the respective homes of the University of Michigan and Ohio State University. The Entertainment and Sports Programming Network (ESPN) ranked the Michigan-Ohio State NCAA Division 1 football rivalry as the greatest North American sports rivalry. Stores in the Toledo area typically display Ohio State and Michigan items adjacently and this merchandise is widely available. Both the yellow Michigan "Block M" and red Buckeye "O" are easily seen and recognized.

\section{Previous research}

An observational study of over 4000 individuals conducted in 2013 in the Toledo metropolitan area demonstrated that university team loyalty was substantially divided among local residents and that no one simultaneously wore apparel from two competing teams (Kruger \& Kruger, 2015). Inspired by these observations, a second study examined reactions to displays of mixed loyalty vs. consistent loyalty. When a research confederate wore clothing featuring both UM and OSU, he elicited more attention and reactions, including staring, double-takes, and comments, than when wearing equivalent outfits featuring just one of the universities (Kruger, Sonnega, Day, Juhasz, Phaneuf, \& Kruger, 2016). These reactions may reflect the violation of a social norm that one cannot simultaneously be a supporter of two competing groups or teams. 


\section{Current Study: Variation in Attention to Displays of Group Allegiance}

The current study examines factors explaining individual variation in attention to public displays of rival group allegiance, whether consistent or mixed. We predict that men, young adults in the typical undergraduate age range (18-25), and those wearing university merchandise themselves will have higher reaction rates to the confederate than women, individuals in other age groups, and individuals not wearing university merchandise respectively. We justify these predictions based on theory and previous research detailed below.

Between-group competition and conflict may be more prominent in the evolved psychology of men than it is for women (for a review, see Van Vugt, De Cremer, \& Janssen, 2007). Among humans' closest living relative, the chimpanzee, males are primarily responsible for coalition formation and territorial defense (Boehm, 1999; Wrangham \& Peterson, 1996). Chimpanzees are highly territorial and intergroup encounters are often hostile (Alexander, 1979; Boehm, 1999; Wrangham \& Peterson, 1996). Like chimpanzees, ancestral human groups were patrilocal, with groups based on male kinship ties and females moving between groups (Goodall, 1986; Wrangham \& Peterson, 1996), thus creating greater incentives for inter-group competition and conflict among males than for females (Van Vugt et al., 2007). Mass graves of humans, mostly males exhibiting injuries from violence, are found dating as far back in time as 200,000 years (Keeley, 1996). As many as $30 \%$ of ancestral men died from intergroup violence (Keeley, 1996), thus intergroup conflict was a potent selection force. Among contemporary cultures, nearly all acts of intergroup aggression are perpetrated by coalitions of men (Atran, 2003; Goldstein, 2003).

The male warrior hypothesis (Van Vugt et al., 2007) argues that the evolutionary history of male coalitional aggression has generated sex differences in perceptions of outgroups and tendencies for inter-group competition, as these competitions are opportunities for men to gain social status, territory, and mates. This hypothesis holds that for men, self-concept is primarily based on associations with larger tribal groups, whereas for women self-concept is primarily based on relationships with other individuals (Van Vugt, 2009). Men are more frequently involved in between-group competition than women are (Pemberton, Insko, \& Schopler, 1996). Men engage in this risky competition because the reproductive benefits may on average outweigh the risks and costs (Buss, 1999). In both contemporary foraging populations (Chagnon, 1988) and urban U.S. communities with street gangs (Palmer \& Tilley, 1995), warriors and gang members often have more sexual partners than other men, although a warrior's aggressiveness does not always predict his reproductive success (Beckerman, Erickson, Yost, Regalado, Jaramillo, Sparks, Iromenga, \& Long, 2009).

Social psychology experiments have found that men are more group oriented, whereas women are more inter-personally oriented (Baumeister \& Sommer, 1997). In experiments with mixed-motive situations, groups solely comprised of men tend to be more competitive than groups solely comprised of women or mixed-sex groups (Wildschut, Pinter, Vevea, Insko, \& Schopler, 2003). In laboratory experiments, men are more likely to engage in competitive between-group interactions than women are (Pemberton, Insko, \& Schopler, 1996). Across three step-level public-goods tasks, men 
contributed more to their group when it was competing with other groups than if there was no intergroup competition, whereas there was no effect of intergroup competition for women (Van Vugt et al., 2007).

Risky behavioral strategies of young males were selected for over time because they tended to aid in mating competition. Young adults in the typical undergraduate age range (18-25 years) may be most prone to inter-group competition and other risky behavior. Those engaged in the most extreme form of modern inter-group competition, the front ranks of every nation's military, are predominantly young adult males (Gardner, 1993). The steep discounting of the future by adolescents and young adults that encourages risky behavior could be a rational response to uncertainty of future outcomes (e.g., Gardner, 1993; Wilson \& Daly, 1997). The risky behavioral strategies of adolescent and young adults, especially males, were selected for because they tended to promote social status and resource control. This facilitated achievements in mating competition, ultimately enhancing reproductive success (Wilson \& Daly, 1993). Men who controlled more resources married younger women, married more women, and produced offspring earlier (Low, 1998).

The shift in the life history allocation of effort from mating to parenting over the life course helps to explain why risky behavior, as well as the peak in the sex difference in mortality rates, peaks in young adulthood (Kruger \& Nesse, 2006). Across our evolutionary history, young men often did not yet have partners or offspring to invest in, and they may have been more attractive to females because they had not yet committed their resources to partners or offspring (Hill \& Kaplan, 1999). Although older men tend to produce most of their offspring within long-term relationships in the foraging Ache, younger men were the predominant fathers of offspring from extra-pair sexual affairs (Hill \& Hurtado, 1996).

Those who are wearing university merchandise themselves may be intentionally expressing their allegiance, and thus independent of other characteristics, may be more sensitive to expressions of allegiance in others. Clothing is an important symbolic social tool conveying information about an individual's affiliations and preferences and influencing judgments by others, especially for young adults (Piacentini \& Mailer, 2004). Wearing items signaling allegiance may act as a heuristic cue, activating coalitional psychology in the bearer and observers (Kurzban \& Leary, 2001; Schaller, Park, \& Faulkner, 2003). We examine these predictions controlling for the effects of the experimental condition, whether the confederate is displaying clothing indicating mixed vs. matching loyalty.

\section{METHOD}

The research team conducted 12 observations at a popular indoor shopping mall in Toledo, Ohio on afternoons during the Fall 2015 collegiate football season when both University of Michigan and Ohio State University had games scheduled that weekend. Allegiance to a university in a community with mixed loyalties may be most salient when the universities are about to engage in competition, 10 of the 12 observations were conducted on Saturday prior to the scheduled football game, two observations were conducted on a Friday before a football game on the following Saturday. Observations 
ended at least an hour before any game began. The same 18-year-old male research confederate walked one circuit of the mall's open corridors carrying a generic shopping bag and wearing merchandise displaying university names (shirt) and logos (hat) in the universities' traditional colors. Across observations, the confederate wore each combination of apparel one fourth of the time (matching OSU, matching UM, UM hat and OSU shirt, OSU hat and UM shirt). Conditions and order were randomly assigned with a coin toss, with one mixed condition and one matched condition observation conducted on each day in the field. Other research team members (two or three observers, depending on day of observations) followed 5-10 meters behind and videotaped the immediate area around the model with a hidden/inconspicuous camera to facilitate coding of behaviors from the recorded footage.

Research team members coded video footage for the sessions they observed. Coders first reviewed each video individually, and then viewed each video simultaneously with the other observers in each session. Coders reached agreement on coding for any discrepancies during group viewing. Coders counted the total number of individuals by gender and approximate age group, under typical undergraduate age, typical undergraduate age (18-25 years old), over typical undergraduate age, to enable the calculation of response rates. Coders indicated whether the subjects were wearing university merchandise themselves and whether each individual made any of the following responses: 1 . Glance at the model for 1 second or less; 2 . Stare at the model for more than 1 second; 3. Double-take (look at the model, look away, then look back at the model); 4. Direct attention of companions to the model non-verbally; 5. Verbally comment to companions; 6 . Verbally comment to model; 7 . Non-verbal gesture directed at the model. If a subject was observed making one or more of these responses, they were coded as reacting to the model. Only individuals whose gaze direction could be determined were included. Research team members did not initiate interactions with other individuals and only responded when engaged. As expected, some subjects engaged in interactions with the confederate, though no subjects engaged in interactions with any other member of the research team.

Each code was converted into a binary variable: Experimental condition (model displays mixed loyalty or matching loyalty); whether a subject was wearing university merchandise him/herself (yes or no); whether a subject appeared to be of typical college age (18-25 years old), and the subject's sex (male or female). Subjects with missing data for any of these variables were excluded from analyses. We conducted a forward conditional binary logistic regression predicting whether or not subjects reacted to the model to examine the hypotheses.

As a form of manipulation check for the initial study and also to gather further insights on the research topic, the first author presented pictures of the confederate to 20 Toledo area residents during casual conversations, after the resident made a comment about sports and/or universities. These were on separate occasions from the reaction observations, although within the same timeframe as the study, in informal private and public settings in Toledo when the first author was engaged in casual conversation with local residents. Local residents included both those who identified as Ohio State fans and those who identified as University of Michigan fans. The photographs were virtually identical, with the confederate presenting a neutral facial expression and an identical background, depicting the confederate wearing all four combinations of apparel. The 
first author asked "What do you think about this?" before presenting each photo, first showing the pictures of matching loyalty displays and then showing the pictures of mixed loyalty displays.

\section{RESULTS}

There were 1327 individuals observed and coded. No individuals were observed to notice the camera or interact with the camera carrier or other observers. The camera view was obscured during one OSU shirt/UM hat condition observation and part of the matching OSU condition observation conducted on the same day. Thus, there were 431 observations in the matching UM condition (32.5\%), 394 observations in the UM shirt, OSU hat condition $(29.7 \%), 320$ observations in the matching OSU condition (24.1\%), and 182 observations in the OSU shirt, UM hat condition (13.7\%). Individuals observed were women $(58.9 \%)$, men $(41.1 \%)$, over college age (64\%), college age (18-25 years, $23 \%)$, and under college age (12.9\%). Forty-seven individuals $(3.5 \%)$ were observed wearing university apparel. Cases with missing data in analytic variables (e.g., observers could not determine age, $\mathrm{n}=35,2.6 \%)$ were not included in the analyses, 1292 subjects were included in the analyses. Reaction rate by subject properties and experimental condition are presented in Table 1.

\begin{tabular}{llllc}
\hline \multicolumn{1}{c}{ Source } & B & SE & Wald & $\boldsymbol{p}$ \\
\hline Subject University Apparel & 1.24 & 0.34 & 13.35 & .001 \\
Experimental Condition & 0.57 & 0.17 & 10.59 & .001 \\
Subject Sex & 0.47 & 0.17 & 7.46 & .006 \\
College Age Subject & 0.47 & 0.19 & 6.10 & .013 \\
Constant & -3.21 & 0.31 & 109.89 & 001 \\
\hline
\end{tabular}

Table 1: Reaction rate by subject properties and experimental condition.

The logistic regression entered all of the potential predictor variables and all were uniquely significant in the final model (See Table 2). Replicating previous analyses, subjects had higher reaction rates in the mixed loyalty condition than in the matching loyalty condition. Controlling for this effect, men had higher reaction rates than women, those appearing to be typical college age (18-25 years old) had higher reaction rates than those in other age groups, and those wearing university related apparel or merchandise had higher reaction rates than those who were not displaying any university related paraphernalia. Thus, the highest rates of reaction were observed for college-aged men wearing university apparel in the mixed loyalty display condition.

\begin{tabular}{lcc}
\hline Subject Sex & Male & Female \\
& $15,1 \%$ & $10,1 \%$ \\
College Age Subject & Yes & No \\
& $16,4 \%$ & $10,9 \%$ \\
Subject University Apparel & Yes & No \\
& $29,8 \%$ & $11,5 \%$ \\
Experimental Condition & Mixed Loyalty & Matching Loyalty \\
& $14,9 \%$ & $10,0 \%$ \\
\hline
\end{tabular}

Table 2: Predictors of whether subject reactions were observed 
The manipulation check exercise reliably produced a typical pattern of results. Subjects would cheer and utter team slogans for the image of the model displaying their favored university team and boo or make a negative remark (e.g., "no, we don't like them!") for the rival university team image. Subjects made contrasting reactions to the images of mixed loyalty displays, including surprise, confusion, disgust, and even anger. Several subjects looked more closely at the image as if to confirm that the confederate was indeed wearing an outfit with mismatched loyalty. Subjects made statements including, "no, you can't do that!," "he's confused," and "he must be blind." The tone of subjects' reactions to the images of the consistent display of their favored team's rival and displays of mixed loyalty were different in that the subjects appeared to enjoy booing the rival team but were rather disturbed or distressed by the display of mixed loyalty.

\section{DISCUSSION}

All hypotheses were supported; men, young adults, and those who are themselves displaying allegiance are more sensitive to expressions of allegiance by others. These effects are significant when controlling for the experimental manipulation. As predicted, men were more likely to notice displays of allegiance than women were. Young adults had higher rates of reaction than other age groups; consistent with the idea that intergroup-competition is most salient in this age range. Those wearing clothing or items displaying university names and logos themselves may be more sensitive to displays of allegiance both because they may feel greater affiliation with the university identity on average than those who are not wearing such items, and because they may be selfconscious that they are displaying such an identity when encountering a potential ally or rival.

Even when the research confederate was wearing apparel with matching loyalty, the allegiance displays elicited greater reactions from these groups than the complementary demographics. There were even incidents when a display of matching loyalty appeared to be provocative. For example, when the research confederate was wearing matching University of Michigan apparel, a man wearing an Ohio State University shirt pulled an Ohio State University hat out of a bag (which he had just purchased), put it on his head, and followed the research confederate at close range for a few minutes. During field observations, team members noted considerable merchandise featuring each of the universities, as well as items portraying the inter-university rivalry. The rivalry and local division in allegiance appears to be a significant feature of the local culture, thus any display of allegiance may attract attention from potential allies and adversaries.

Our study advances the literature on coalitional psychology and behavior with novel hypotheses tested in a novel paradigm. We demonstrate predicted variation in real world reactions to displays of allegiance, complementing research using laboratory based experimental studies and documentation of cultural and historical patterns of intergroup competition. We demonstrate the value of research combining controlled experimental manipulations with live naturalistic observations. Laboratory environments may provide more control over conditions and facilitate more comprehensive documentation of events, however our naturalistic experiment has the advantage of ecological validity and 
eliminates demand characteristics and other challenges associated with laboratory-based experiments.

Critics may charge that this pattern of results could be explained by social identity theories or some other psychological theory, however these proximate explanations are not in opposition to the notion of an evolved coalitional psychology. Psychological adaptations shaped by evolutionary selection pressures will necessarily have some proximal mechanism or psychological process influencing behavior. The psychological literature reviewed in the introduction section reveals the importance of intergroup competitions in shaping social identity. We demonstrate the effect of breaking social norms regarding group loyalty with the greater rates of reaction to the displays of mixed allegiance compared to consistent allegiance. The mixed allegiance displays are surprising not just because they are novel, they are both novel and surprising because evolved coalitional psychology usually prevents individuals from committing the faux pas of simultaneously proclaiming loyalty to two bitterly competitive rivals. The manipulation check confirms that the mixed allegiance outfits are surprising because of the violation of coalitional norms that one can only have true allegiance with one group or team in a set of competitors. This is echoed in the verbal comments in response to the confederate directly referencing the display of mixed allegiance, e.g., "Hey, that guy is wearing a $U$ of $M$ shirt and an Ohio State hat!" This suggests that heightened attention stems from the violation of a social norm that one can only have true allegiance with one group or team in a set of competitors. Individuals who display mixed loyalties may be notable, as they could be potential defectors in active competition.

\section{LIMITATIONS}

We used a digital video recording to provide objective and verifiable assessments of reactions. However, this method likely underestimated the rates of reactions. Compared to a human observer, the video allowed for a narrow view, brief inclusion of individuals, and low sound quality. Observers noted witnessing reactions, including several verbal statements that were not documented in the footage or represented in the coded data. This restricted range applies to all conditions and thus would not bias the results.

\section{CONCLUSION}

Our results advance understanding of coalitional psychology and behaviors related to sports team rivalries. This study provides evidence that men, young adults, and those who are themselves displaying allegiance are more sensitive to expressions of allegiance by others. We also demonstrate the value of research combining controlled experimental manipulations with live naturalistic observations. The novel methodological paradigm of confederates wearing clothing expressing consistent or mixed loyalty may be suitable for examining contrasts in affiliations across a broad range of topical content. For example, confederates could display campaign logos for particular political candidates and organizations associated with partisan affiliations. 


\section{REFERENCES}

Alexander, R.D. (1979). Darwinism and human affairs. Seattle, WA: University of Washington Press.

Atran, S. (2003). The genesis of suicide terrorism. Science, 299, 1534-1539. DOI

Beckerman, S., Erickson, P.I., Yost, J., Regalado, J., Jaramillo, L., Sparks, C., Iromenga, M., \& Long, K. (2009). Life histories, blood revenge, and reproductive success among the Waorani of Ecuador. Proceedings of the National Academy of Sciences, 106, 8134-8139. DOI

Baumeister, R.F., \& Sommer, K.L. (1997). What do men want? Gender differences and the two spheres of belongingness. Psychological Bulletin, 122, 38-44. DOI

Boehm, C. (1999). Hierarchy in the forest. London: Harvard University Press.

Bogardus, E.S. (1924). Fundamentals of Social Psychology. New York: Century.

Brewer, M.B. (1979). Ingroup bias in the minimal intergroup situation: A cognitive-motivational analysis. Psychological Bulletin, 86, 307-324. DOI

Buss, D.M. (1999). Evolutionary psychology. London: Allyn \& Bacon.

Chagnon, N.A. (1988). Life histories, blood revenge, and warfare in a tribal population. Science, 239, 985-992. DOI

Gardner, W. (1993). A life-span rational-choice theory of risk taking. In N. J. Bell and R. W. Bell (Eds.), Adolescent Risk Taking (pp. 66-83). Newbury Park, CA: Sage Publications.

Goldstein, J. (2003). War and gender: How gender shapes the war system and vice versa. Cambridge, UK: Cambridge University Press.

Goodall, J. (1986). TheChimpanzees of Gombe: Patterns of Behavior. Harvard University Press. Cambridge, MA.

Hill, K. \& Hurtado, M. (1996). Ache Life History: The Ecology and Demography of a Foraging People. New York: Aldine de Gruyter.

Hill, K. \& Kaplan, H. (1999). Life History traits in humans: Theory and empirical studies. Annual Review of Anthropology, 28, 397-438. DOI

Keeley, L. (1996). War before Civilization. New York: Oxford University Press.

Kenrick, D.T., N.P. Li \& J. Butner. (2003). Dynamical evolutionary psychology: Individual decision rules and emergent social norms. Psychological Review, 110, 3-28. DOI

Kruger, D.J., \& Kruger, J.S. (2015). An ethological assessment of allegiance to rival universities in an intermediate city. Human Ethology Bulletin, 30, 21-29.

Kruger, D.J., \& Nesse, R. M. (2006). An evolutionary life-history framework for understanding sex differences in human mortality rates. Human Nature, 17, 74-97. DOI

Kruger, D.J., Sonnega, P.A., Day, M.M., Juhasz, D., Phaneuf, C.V., \& Kruger, J.S. (2016, May). You can't root for both teams: Reactions to coalitional norm violations. Oral presentation, Association for Psychological Science, Chicago, IL.

Kruger, D.J., Wang, X. T., \& Wilke, A. (2007). Towards the development of an evolutionarily valid domain-specific risk-taking scale. Evolutionary Psychology, 5, 570-583. DOI 
Kurzban, R. \& Leary, M.R. 2001. Evolutionary ori- gins of stigmatization: The functions of social exclusion. Psycholgical. Bulletin, 127, 187-208. DOI

Lindquist, D. C. (2006). "Locating" the nation: Football game day and American dreams in central Ohio. Journal of American Folklore, 119, 444-488. DOI

Low, B. (1998). The evolution of human life histories. In C. Crawford \& D. Krebs (Eds.) Handbook of Evolutionary Psychology: Issues, Ideas, and Applications (pp. 131- 161). Mahwah, NJ: Lawrence Erlbaum Associates.

Ostrom, T.M., \& Sedikides, C. (1992). The outgroup homogeneity effect in natural and minimal groups. Psychological Bulletin, 112, 536-552. DOI

Pemberton, M.B., Insko, C.A., \& Schopler, J. (1996). Memory for and experience of differential competitive behavior of individuals and groups. Journal of Personality and Social Psychology, 71, 953-966. DOI

Piacentini, M. and Mailer, G. (2004), Symbolic consumption in teenagers' clothing choices. Journal of Consumer Behaviour, 3, 251-262. DOI

Richardson, B., \& O'Dwyer, E. (2003). Football supporters and football team brands: A study in consumer brand loyalty. Irish Marketing Review, 16, 43-52.

Ruffle, B.J., \& Sosis, R. (2006). Cooperation and the in-group-out-group bias: A field test on Israeli kibbutz members and city residents. Journal of Economic Behavior and Organization, 60, 147-163. DOI

Schaller, M., Park, J.H., \& Faulkner, J. (2003). Prehistoric dangers and contemporary prejudices. European Review of Social Psychology, 14, 105-137. DOI

Sherif, M. (1966). In common predicament: Social psychology of intergroup conflict and cooperation. Boston: Houghton Mifflin.

Tajfel, H., \& Turner, J.C. (1979). An integrative theory of intergroup conflict. In W.G. Austin \& S. Worchel (Eds.), The social psychology of intergroup relations (pp. 33-47). Monterey, CA: Brooks/Cole.

Trice, H. M., \& Beyer, J. M. (1984). Studying organizational culture through rites and ceremonials. Academy of Management Review, 9, 653-669. DOI

van der Dennen, J.M.G. (2002). Evolutionary theories of warfare in preindustrial foraging societies. Neuroendocrinology Letters, 23, (supplement 4), 55-65.

Van Vugt, M. (2009). Sex differences in intergroup competition, aggression, and warfare. Annals of the New York Academy of Sciences, 1167, 124-134. DOI

Van Vugt, M., De Cremer, D., \& Janssen, D. P. (2007). Gender differences in cooperation and competition: the male-warrior hypothesis. Psychological Science, 18, 19-23. DOI

Wetherell, M. (1982). Cross-cultural studies of minimal groups: Implications for the social identity theory of intergroup relations. In $\mathrm{H}$. Tajfel (ed.), Social identity and intergroup relations (pp. 207-240). Cambridge, UK: Cambridge University Press.

Wilson, M. \& Daly, M. (1993). Lethal Confrontational Violence among Young Men. In N.J. Bell \& R.W. Bell (eds.), Adolescent Risk Taking (pp. 84-106). Newbury Park, California: Sage Publications. 
Wilson, M. \& Daly, M. (1997). Life expectancy, economic inequality, homicide, and reproductive timing in Chicago neighbourhoods. British Medical Journal, 314, 1271-1274. $\underline{\mathrm{DOI}}$

Wildschut, T., Pinter, B., Vevea, J.L., Insko C.A., \& Schopler, J. (2003). Beyond the group mind: A quantitative review of the interindividual-intergroup discontinuity effect. Psychological Bulletin, 129, 698-722. DOI

Winegard, B., \& Deaner, R.O. (2010). The evolutionary significance of Red Sox Nation: Sport fandom as a byproduct of coalitional psychology. Evolutionary Psychology, 8, 432-446. $\underline{\mathrm{DOI}}$

Wrangham, R., \& Peterson, D. (1996). Demonic males: Apes and the origins of human violence. London: Bloomsbury. 